\title{
Diarrhea Risk Factors Associated with Water, Sanitation and Hygiene Among the Under Five in Kasarani, Nairobi County
}

\author{
Humphrey Mbuti Kimani ${ }^{1}$, Daniel Nyagetiria Akunga ${ }^{2}$, Stephen Obiero Anyango ${ }^{3}$, \\ Taratisio Ndwiga $^{4}$ \\ ${ }^{1}$ School of Public Health, Technical University of Kenya, Nairobi, Kenya \\ ${ }^{2}$ School of Public Health, Kenyatta University, Nairobi, Kenya \\ ${ }^{3}$ Department of Environmental and Biosystems Engineering, University of Nairobi, Nairobi, Kenya \\ ${ }^{4}$ School of Public Health, Moi University, Eldoret, Kenya
}

\section{Email address:}

kimanihumphrey@yahoo.co.uk (H. M. Kimani), Nyakungaddn@gmail.com (D. N. Akunga), Stephen.obiero@uonbi.ac.ke (S. O. Anyango), taratisondwiga@gmail.com (T. Ndwiga)

\section{To cite this article:}

Humphrey Mbuti Kimani, Daniel Nyagetiria. Akunga, Stephen Obiero Anyango, Taratisio Ndwiga. Diarrhea Risk Factors Associated with Water, Sanitation and Hygiene Among the Under Five in Kasarani, Nairobi County. Central African Journal of Public Health.

Vol. 5, No. 6, 2019, pp. 272-279. doi: 10.11648/j.cajph.20190506.18

Received: September 24, 2019; Accepted: October 16, 2019; Published: October 23, 2019

\begin{abstract}
Provision of quality water continues to be a challenge in the developing Counties particularly in the informal settlements and Kenya is not an exception. This study assessed diarrhea disease attributable to water, sanitation and hygiene (WASH) among the under five in Kasarani, Nairobi County. The main objective of this study was to establish the association between diarrhea among the under five and Water, Sanitation and hygiene. To achieve this goal Kasarani was categorized into four study environs namely low density high income, Medium density middle income, high density low income and informal settlement low income. Structured questionnaire and hygiene checklist were used as data collection instruments. Association and significant differences between variables were determined using inferential statistics and Chi-square tests. To compare quantitative variables (ANOVA) test was preferred. This study determined that water consumed in Kasarani was a risk for childhood diarrhea $(\mathrm{p}=0.019)$. Tap water showed a significantly higher contamination $13.7 \%$ than household water container $7.2 \%$ for T. Coli Bacteria. The amount of water a household consumed per day was an important risk factor for childhood diarrhea $(\mathrm{P}=0.001)$. Overall, Age of a child $(\mathrm{P}=0.046)$, water treatment method $(\mathrm{P}=0.002)$, method of storage of solid waste $\mathrm{P}<0.001$, quantity and frequencies of water supply $(\mathrm{P}<0.001)$ were also found to be the most important risk factors for childhood diarrhea. The study concluded that there was a relationship between childhood diarrhea and water, sanitation and hygiene in Kasarani. The study recommended that Nairobi water and Sewerage Company institute programs that will facilitate adequate and wholesome water supply to HDLI and ISLI residential environs respectively.
\end{abstract}

Keywords: Diarrhea Diseases, Water Quality and Quantity, Water-borne Diseases, Water, Sanitation and Hygiene

\section{Introduction}

Diarrheal disease kills an estimated 2.2 million people each year [1]. Among infectious diseases, Diarrhea is ranked as the third leading cause of both mortality and morbidity [2]. Young children are especially vulnerable bearing $68 \%$ of the total burden of diarrhea disease [3]. Among children less than five years, diarrhea accounts for $17 \%$ of all deaths [4]. The infectious agents associated with diarrhea disease are transmitted chiefly through the faecal oral route [5]. The wide variety of bacteria, viral and protozoa pathogens excreted in the faeces of humans and animal are known to cause diarrhea. Among the most important of these are Escherichia coli (E. coli), Salmonella sp; Shigella sp; Campylobacter jejuni, Vibrio cholera, Rotavirus, Norovirus, Giandia lamblia, Cryptosporidium sp; and Entamoeba Histolytica [4]. Bacteria agents as a group are 
believed to cause a majority of diarrhea diseases in developing countries, while viral and protozoa agents tend to cause more cases in developed countries [6].

Many of the diarrhea agents are potentially waterborne transmitted through ingestion of contaminated water [6]. Intervention for the prevention and control of diarrheal diseases not only include enhanced water quality but also steps to improve sanitation, increase the quality and improve access to water supply, promote hand washing and other hygiene practices within domestic and community settings [7]. Health authorities generally accept that microbiologically safe water plays an important role in preventing outbreaks of waterborne diseases [6]. Accordingly, the most widely accepted guidelines for water quality allow no detectable level of harmful pathogens at the point of distribution [3]. However, an estimated 1.1 billion people lack access to improved water supplies [8]. In settings that are not served by reliable water treatment and distribution systems, diarrhea disease is often endemic [8]. With improvement in the quality of drinking water, there is evidence of increased health benefits [9]. According to global water, sanitation and hygiene fast facts, water, sanitation and hygiene have the potential to prevent at least $9.1 \%$ of the global disease burden and $6.3 \%$ of all deaths [10]. Further, improved sanitation could save the lives of 1.5 Million children per year who would otherwise succumb to diarrhea diseases [10]. Unsafe drinking water, inadequate availability of water for hygiene and lack of access to sanitation together contribute to about $88 \%$ of the deaths from diarrhea diseases or more than 1.5 million of the 1.9 million on children younger than 5 years of age who perish from diarrhea each year mostly in developing countries [11]. This amounts to $18 \%$ of all the deaths of children under the age of five leading to more than 5,000 children dying every day as a result of diarrhea diseases.

In Africa and especially Sub-Saharan Africa, diarrhea' diseases account for over $90 \%$ of deaths in children below five years old [12]. This has been attributed to lack of safe drinking water, sanitation and hygiene as well as poor nutrition. Accordingly, improved water sources reduce diarrhea morbidity by $21 \%$, improved sanitation by $37.5 \%$ and hand washing by as much as $35 \%$ [14]. Regions with the lowest coverage of improved sanitation in 2006 were SubSaharan Africa (31\%), Southern Asia (33\%) and Eastern Asia $(65 \%)$. In Kenya, diarrheal disease is the major cause of childhood morbidity and mortality [16]. According to the National Policy Guidelines to redouble diarrhea disease management and control efforts by the Ministry of Public Health and Sanitation, untreated diarrhea kills and is the third leading cause of death in children under five years in Kenya [17]. The policy also observes that, while many Kenyans have gained access to safe drinking water, the majority still lack access to proper sanitation. Globally, Oral rehydration therapy has however dramatically decreased the mortality associated with diarrhea but has had little effect on morbidity estimated to be approximately 4 billion cases per year [17].

With continued high attack rates, diarrheal disease is also an enormous economic burden resulting in significant direct costs to the health sector and patients for treatment as well as in cost time at school, work and productive activities [18]. An estimated $94 \%$ of the diarrhea burden of disease is attributable to the environment and associated with risk factor such as unsafe drinking water, lack of sanitation and poor hygiene [19]. Traditionally, economic evaluation of water and sanitation has focused on infrastructural improvements- mainly construction of facilities to improve water supplies and excreta disposal. According to the data available at the City Council of Nairobi, Epidemiology and Disease control section, diarrheal diseases remain the second cause of morbidity in the children under five years in Nairobi with Kasarani reporting an average of 1000 cases of diarrhea per month [20]. Arising from the observed serious public health problem, this research intended to establish whether there was an association between water, sanitation, hygiene and diarrheal diseases among the under five years of age in Kasarani, Nairobi County.

\section{Methodology}

\subsection{Study Design}

This study was a cross-sectional design. The design was chosen since it was meant to determine risk factors of diarrhea among the under five in Kasarani and examine the association with water, sanitation and hygiene. Hence a reconnaissance survey was initially conducted to identify the households and health facilities to be sampled. The residential estates of the study area were clustered into four study environs based on the social, economic and environmental sanitation characteristics. The Simple random technique was used to select the participating estates according to probability proportionate to sample size. To select participating households in each of the selected estate, Simple random technique was again employed according to probability proportionate to sample size.

\subsection{Study Setting}

The study was carried out at Kasarani, Nairobi County. Kasarani is about $10 \mathrm{KM}$ from the City Centre along Thika road and in the Northern part of Nairobi County. The SubCounty has seven wards. They are: Githurai, Kariobangi, Kahawa, Kasarani, Korogocho, Roysambu and Ruaraka. Kasarani has a population of approximately 525,000 people and covers an area of $86 \mathrm{KM} 2$. The area has approximately 10,500 , households which are predominantly residential estates ranging from low density high income to informal settlement low income. The water supply source is Nairobi Water and Sewerage Company. Water distribution is mostly through plastics pipes while the drainage system is through the septic tanks, soaked pits and pit latrines. There is no established method of solid waste management and most residents practice indiscriminate solid waste dumping.

\subsection{Study Population}

The study targeted all the children below age of five 
residing in Kasarani. The respondent was the child care giver at the time of the study. However, since the study targeted child caregivers as respondents the target population was 10,500 households in the area. For ease of the study, the residential estates were clustered into four study environs based on the Social/environmental characteristics namely Low Density High Income (LDHI), Medium Density Middle Income (MDMI), High Density Low Income HDLI) and Informal Settlement Low Income ISLI) respectively.

\subsection{Sample Size}

Overall, a total of 199 eligible households representing 31, 53, 56 and 59 households in the LDHI, MDMI, HDLI and ISLI were sampled. Simple random technique was used to select participating estates according to probability proportionate to sample size. Before selecting sample environs, implicate stratification was achieved through first stage Sampling by sorting estates using a socio economic status indicator. To select participating household in each of the selected estate, simple random sampling technique was again employed according to probability proportionate to sample size.

\subsection{Data Collection}

Each household was visited for data collection and sanitation inspection using a structural questionnaire. The respondents were asked to identify the source, frequency and quality of water used in the household as well as type and form of sanitation facilities available for other use. Sanitary inspections were conducted through visual assessment of the infrastructures and sanitary state surrounding the household water supply, water holding containers, among others taking into account the sanitary aspects and practices in water handling that posed an actual or potential risk to water quality, health and wellbeing of the child. Further the respondents were asked whether any of the children in the household had experienced diarrhea in the last one month prior to the visit. If the answer was yes the respondent was asked the age of the child at the time of infection, whether treatment was sought and from where and the symptoms and signs of the episode. For the hospital data, health facilities operating within the selected estates were visited to review childhood diarrhea related mobility and mortality. These facilities were purposefully and conveniently selected and matched with the particular selected estate as identified in the initial survey. To determine level of bacterial contamination, a water sample was collected from each household visited where a $250 \mathrm{ml}$ glass stopper bottles were used. The bacteriological examination of the water sample was analyzed at the food and water sampling laboratory of the Nairobi County.

\section{Results}

\subsection{Introduction}

The study sought to assess diarrhea disease attributable to Water, Sanitation and Hygiene among the under five in Kasarani, Nairobi County. To achieve this goal, the study area was categorized in four study environs namely low density high income (LDHI), medium density middle income (MDMI), high density low income (HDLI and informal settlement low income (ISLI). Below is the summery of the results:

\subsection{Demographic Characteristics of the Study Area}

Table 1. Socio-Demographic characteristics by Residential Environs.

\begin{tabular}{|c|c|c|c|c|}
\hline \multirow{2}{*}{ Variables } & \multicolumn{4}{|c|}{ Residential environs } \\
\hline & LDHI (31) & MDMI (53) & HDLI (56) & ISLI (59) \\
\hline Child mean age in months (mean) & 35.64 & 37.56 & 35.76 & 32.16 \\
\hline & $(48.4 \%) \mathrm{F}(11)$ & $(50.9 \%) \mathrm{F}(27)$ & $(58.9 \%) \mathrm{F}(30)$ & $(52.5 \%) \mathrm{F}(35)$ \\
\hline Cnina s sex & $51.6 \%) \mathrm{M}(13)$ & $(49.1 \%) \mathrm{M}(26)$ & $(41.1 \%) \mathrm{M}(21)$ & $(47.5 \%) \mathrm{M}(32)$ \\
\hline \multicolumn{5}{|l|}{ Respondents Education Level } \\
\hline Primary (21) & $5(16.1 \%)$ & $8(15.0 \%)$ & $18(32.2 \%)$ & $15(25.4 \%)$ \\
\hline Secondary (24) & $7(22.6 \%)$ & $25(47.2 \%)$ & $27(48.2 \%)$ & $14(23.7 \%)^{\prime}$ \\
\hline \multicolumn{5}{|l|}{ Marital Status } \\
\hline Married (33) & $12(38.7 \%)-$ & $31(58.5 \%)$ & $30(53.6 \%)$ & $25(42.4 \%)$ \\
\hline Single (21) & $10(32.3 \%)$ & $15(28.3 \%)$ & $10(17.8 \%)$ & $18(30.5 \%)$ \\
\hline Other (24) & $9(29.0 \%)$ & $7(13.2 \%)$ & $16(28.6 \%)$ & $16(27.1 \%)$ \\
\hline \multicolumn{5}{|l|}{ Household Income } \\
\hline Below Kshs. 25000 (25) & $7(22.6 \%)$ & $21(39.6 \%)$ & $30(53.6 \%)$ & $32(54.3 \%)$ \\
\hline Kshs. 25,001-40,000 (30) & $11(35.5 \%)$ & $19(35.8 \%)$ & $20(35.7 \%)$ & $22(37.2 \%)$ \\
\hline
\end{tabular}

A total of 195 children were recorded in the study area. The mean child's age in months was highest in MDMI (37.56)) and least in ISLI (32.16) respectively. With regard to child's sex, the highest proportion of girls was in HDLI $(58.9 \%)$ and lowest in LDHI (48.4\%) while the male constituted LDHI $(51.6 \%)$ and HDLI $(41.1 \%)$ respectively suggesting a female to male ratio of $1: 1$. For education, most respondents had attained secondary level and above with majority coming from MDMI. However, for the respondents with primary education level, majority were still from the same residential study environ (15.0\%). Most respondents from MDMI (58.5\%) and HDLI (53.6\%) were married. 
Those divorced, separated and windowed were mainly from LDHI (29.0\%) and HDLI (28.6\%) respectively. Majority of the respondents in this study indicated their household monthly income as between Ksh 20,001 and Ksh 40,000.
LDHI registered the highest average household monthly income with $41.9 \%$ earning an average net monthly income of above Ksh 40,000. ISLI recorded the least household income in this category with only $8.5 \%$.

\subsection{Diarrhea Risk Factors Associated with WASH Conditions in the Study Environs}

Table 2. Water Supply and Quality indicators.

\begin{tabular}{|c|c|c|c|c|c|}
\hline \multirow{2}{*}{ Variable } & \multicolumn{4}{|c|}{ Residential environs } & \multirow[t]{2}{*}{ Significance leve } \\
\hline & LDHI (31) & MDMI(53) & HDLI (56) & ISLI (59) & \\
\hline \multicolumn{6}{|c|}{ Amount of water a family uses per day } \\
\hline Mean Liters/Day & 92.64 & 80.26 & 78.53 & 60.75 & $\mathrm{P}=0.001$ \\
\hline \multicolumn{6}{|c|}{ Whether households treat water before use } \\
\hline Yes & $22(70.96 \%)$ & $38(71.7 \%)$ & $45(80.4 \%)$ & $54(91.5 \%)$ & \multirow{2}{*}{$\mathrm{p}=0.001$} \\
\hline No. $5(8.5 \%)$ & $9(29.04 \%)$ & $15(28.3 \%)$ & $11(19.6 \%)$ & $5(8.5 \%)$ & \\
\hline \multicolumn{6}{|c|}{ Methods of water treatment } \\
\hline Other & $5(16.1 \%)$ & $20(37.7 \%)$ & $18(32.1 \%)$ & $24(40.7 \%)$ & $\mathrm{P}=0.002$ \\
\hline \multicolumn{6}{|c|}{ Water shortage frequency } \\
\hline Less than three days & $20(64.5 \%)$ & $40(75.4 \%)$ & $37(66.1 \%)$ & $43(72.9 \%)$ & \multirow[t]{2}{*}{$\mathrm{p}-0.001$} \\
\hline Other & $11(35.5 \%)$ & $13(24.6 \%)$ & $19(33.9 \%)$ & $16(27.1 \%)$ & \\
\hline
\end{tabular}

Table 2 above describes the state of water supply and quality in Kasarani. Results as obtained indicated that all the households had water supply. Significant associations occurred between quantity of water use and environ $(\mathrm{P}<0.05)$, water treatment and environ $(\mathrm{p}<0.05)$, and frequency of water shortage and environ $(p<0.05)$ respectively. These results further indicated that ISLI had less favorable attributes with regard to water supply and quantity compared to LDHI study environs.

\subsection{Diarrhea Occurrences in the Study Area by Residential Environs}

Table 3. Diarrhea occurrence of the under five disaggregated by study area.

\begin{tabular}{|c|c|c|c|c|c|}
\hline \multirow{2}{*}{$\begin{array}{l}\text { Variable } \\
\text { Diarrhea episodes }\end{array}$} & \multicolumn{4}{|c|}{ Residential environs } & \multirow{2}{*}{ Significance level } \\
\hline & LDHI(31) & MDMI(53) & HDLI (56) & ISLI(59) & \\
\hline \multicolumn{6}{|c|}{ Occurrence of Diarrhea in the last one month } \\
\hline Yes & $5(16.1 \%)$ & $20(37.7 \%)$ & $23(41.1 \%)$ & $29(49.2 \%)$ & \multirow{2}{*}{$\mathrm{p}=0.001$} \\
\hline No & $26(83.9 \%)$ & $33(62.3 \%)$ & $33(58.9 \%)$ & $30(50.8 \%)$ & \\
\hline \multicolumn{6}{|c|}{ Age of the child during infection } \\
\hline Months (mean) & 36 & 34.68 & 30 & 29.16 & $\mathrm{p}=0.046$ \\
\hline \multicolumn{6}{|l|}{ Attribution to the Diarrhea } \\
\hline Water quality & $17(54.8 \%)$ & $26(49.1 \%)$ & $26(46.4 \%)$ & $20(33.9 \%)$ & $\mathrm{P}=0.905$ \\
\hline
\end{tabular}

This research sought to establish whether the under-fives in the study area had experienced diarrhea episodes in the last one month of the study. Results indicated that diarrhea had occurred with significance association with residential environ $(p=0.001)$. Older children were more affected in
LDHI than in ISLI. However, when respondents were asked what they attributed occurrence of the diarrhea to, there was no significant difference in response with all areas reporting both poor sanitation and water quality as possible contributing factors $(\mathrm{p}>0.05)$.

\subsection{Household Sanitation Coverage}

Table 4. Household sanitation coverage in the study area environs.

\begin{tabular}{|c|c|c|c|c|c|}
\hline \multirow{2}{*}{$\begin{array}{l}\text { Variable } \\
\text { Type of the toilet }\end{array}$} & \multicolumn{4}{|c|}{ Residential environs } & \multirow{2}{*}{ Sig. Level } \\
\hline & LDIII(31) & MDMI(53) & HDLI(56) & ISLI(59) & \\
\hline Flush toilet & $26(83.9 \%)$ & $36(67.9 \%)$ & $40(71.4 \%)$ & $10(16.9 \%)$ & \multirow{2}{*}{$\mathrm{p}=0.001$} \\
\hline Other & $5(16.1 \%)$ & $17(32.1 \%)$ & $16(28.6 \%)$ & $49(83.1 \%)$ & \\
\hline \multicolumn{6}{|c|}{ Adequacy of the toilet facility } \\
\hline Adequate & $25(80.64 \%)$ & $40(75.5 \%)$ & $42(75.0 \%)$ & $47(79.7 \%)$ & \multirow{2}{*}{$\mathrm{p}=0.001$} \\
\hline Not Adequate & $6(19.36 \%)$ & $13(24.5 \%)$ & $14(25.0 \%)$ & $12(20.3 \%)$ & \\
\hline \multicolumn{6}{|c|}{ Washing of hands after visiting the toilets } \\
\hline Always & $23(74.2 \%)$ & $44(83.1 \%)$ & $45(80.3 \%)$ & $40(67.7 \%)$ & \multirow{2}{*}{$\mathrm{P}=0.649$} \\
\hline Other & $8(25.8 \%)$ & $9(16.9 \%)$ & $11(19.7 \%)$ & $19(32.3 \%)$ & \\
\hline \multicolumn{6}{|c|}{ Disposal of solid waste } \\
\hline Polythene bag & $26(83.8 \%)$ & $39(73.60 \%)$ & $40(71.4 \%)$ & $17(28.8 \%)$ & \multirow{2}{*}{$\mathrm{P}=0.001$} \\
\hline Other & $5(16.2 \%)$ & $14(26.4 \%)$ & $16(28.6 \%)$ & $42(71.2 \%)$ & \\
\hline
\end{tabular}


The study was to determine the level of household's sanitation coverage in the study area. Results as contained in table 4 above established that there was good household sanitation coverage. Type of toilet facility, adequacy and household sanitation practices were significantly associated with residential environ. This meant that living in ISLI diminished one's opportunities to quality and adequate sanitation facilities.

\subsection{Household and Personal Hygiene Practices}

Table 5. Household and personal hygiene behavior in the study area by residential environ.

\begin{tabular}{|c|c|c|c|c|c|}
\hline \multirow{2}{*}{$\begin{array}{l}\text { Variable } \\
\text { Issue/statement }\end{array}$} & \multicolumn{4}{|c|}{ Residential environs } & \multirow{2}{*}{ Significance level } \\
\hline & LDIH (31) & MDMI (53) & HDLI(56) & ISLI (59) & \\
\hline \multicolumn{6}{|c|}{ Insect vectors in the house may pose ill health to a child } \\
\hline Yes & $31(100.0 \%)$ & $53(100 \%)$ & $55(98.2 \%)$ & $59(100 \%)$ & $\mathrm{p}=0.463$ \\
\hline \multicolumn{6}{|c|}{ Uncollected solid waste pose a health risk to a child's health } \\
\hline Yes & $31(100.0 \%)$ & $53(100 \%)$ & $52(98.3 \%)$ & $58(98.3 \%)$ & $\mathrm{p}=0.169$ \\
\hline
\end{tabular}

This research was to establish the level of personal hygiene practices and health awareness among the respondents in the households across the study area. Results obtained showed high level of personal hygiene practices and health awareness among the respondents. However, whether the presence of insect vectors in the house and uncollected solid waste posed ill health to a child did not significantly associate with the residential environs ( $p>0.05)$.

\subsection{Drinking Water and Household Water Storage Container Sanitary Inspections}

Table 6. Shows household water storage container in the study area by residential environs.

\begin{tabular}{|c|c|c|c|c|c|}
\hline \multirow{2}{*}{$\begin{array}{l}\text { Variable } \\
\text { Issue/statement }\end{array}$} & \multicolumn{4}{|c|}{ Residential environs } & \multirow{2}{*}{ Significance level } \\
\hline & LDHI (31) & MDMI (53) & HDLI (56) & ISLI (59) & \\
\hline \multicolumn{6}{|c|}{ Type of the water container } \\
\hline Plastic & $25(80.6 \%)$ & $43(81.2 \%)$ & $50(89.3 \%)$ & $49(83.1 \%)$ & \multirow{2}{*}{$\mathrm{p}=0.061$} \\
\hline Other & $6(19.4 \%)$ & $10(18.8 \%)$ & $6(10.7 \%)$ & $10(16.9 \%)$ & \\
\hline \multicolumn{6}{|c|}{ Water container covered or not } \\
\hline Yes & $31(100.0 \%)$ & $52(98.1 \%)$ & $53(94.6 \%)$ & $55(93.2 \%)$ & $\mathrm{p}=0.538$ \\
\hline \multicolumn{6}{|c|}{ Accessibility of the water container by other people } \\
\hline
\end{tabular}

This study sought to establish the sanitary state of the household water storage containers. The findings indicated that households had water containers in their houses. Plastic water containers were most preferred in the storage of water across the four residential environs. However, type of water container, whether the container was covered and whether water containers were accessed by other people did not significantly differ across the four residential environs $(\mathrm{P}>0.005)$. Majority of the households had adequate and quality water containers for water storage.

\subsection{Household Water Contamination Level}

Table 7. Level of bacterial contamination in water samples for Kasarani study environs.

\begin{tabular}{lllllll}
\hline \multirow{2}{*}{ Residential cluster } & HHWC & & HHWT & & Total \\
\cline { 2 - 6 } & E-coli & T-coli & E-coli & T-coli & E-coli & T-coli \\
\hline LDHI & BDL & BDL & BDL & BDL & BDL & BDL \\
MDMI & BDL & $3.8 \%$ & $5.7 \%$ & $7.6 \%$ & $5.7 \%$ & $5.8 \%$ \\
HDLI & $5.7 \%$ & $3.6 \%$ & $3.6 \%$ & $7.1 \%$ & $8.9 \%$ & $11.0 \%$ \\
ISLI & $11.9 \%$ & $13.6 \%$ & BDL & $15.2 \%$ & $12.7 \%$ & $14.0 \%$ \\
Total & $8.9 \%$ & $7.2 \%$ & $4.8 \%$ & $13.7 \%$ & $13.3 \%$ & $16.1 \%$ \\
\hline
\end{tabular}

Water sampled from LDHI were all negative indicating for E. Coli and T. Coli respectively. For the water sampled from MDMI, HDLI and ISLI, the microbial contamination was detected in $13.3 \%$ and $16.1 \%$ of the water samples for E-Coli and T-Coli respectively. Approximately $8.9 \%$ and $7.2 \%$ of water sample collected directly from MDMI, HDLI and ISLI household water containers had both E-Coli and T-Coli bacteria respectively. Further $4.8 \%$ and $13.7 \%$ of the water samples collected directly from the MDMI, HDLI and ISLI household tap water were also positive. The organism ranged between 1 organism $/ 100 \mathrm{ml}$ of water to 180 organism/100ml of water with a mean of 48.2 organism $/ 100 \mathrm{ml}$ for both Total Coli and E-Coli respectively.

The study established that non-compliance was significantly higher for household water tap $13.7 \%$ Total Coli Bacteria compared to MDMI, HDLI and ISLI household water container $7.2 \%$ respectively $(p=0.019)$. Across the study environs, the study further established a significance difference for non compliance (p-0.002). According to microbial guidelines set by WHO/UNICEF (2008) and also EMCA (1999) Water quality regulations, Total and fecal Coli 
form bacteria must not be detectable in any $100 \mathrm{ml}$ sample collected from drinking water sources.

\subsection{Factors Associated with Social Demographic and Household Childhood Diarrhea}

Table 8. Relationships between several social demographic factors and childhood Diarrhea.

\begin{tabular}{|c|c|c|c|}
\hline Indicator variable & Number of children & Diarrhea prevalence & Significance \\
\hline \multicolumn{4}{|l|}{ Caregiver level of education } \\
\hline Primary & 21 & 0.11 & \multirow{3}{*}{$\mathrm{p}=0.551$} \\
\hline Secondary & 24 & 0.12 & \\
\hline Other & 28 & 0.14 & \\
\hline \multicolumn{4}{|l|}{ Marital status } \\
\hline Married & 33 & 0.17 & \multirow{2}{*}{$\mathrm{p}=0.513$} \\
\hline Single & 21 & 0.11 & \\
\hline \multicolumn{4}{|c|}{ Household average net monthly income } \\
\hline$<$ Kshs. 25,000 & 25 & 0.13 & \multirow{3}{*}{$\mathrm{p}=0.740$} \\
\hline Kshs. 25,000 --Kshs. 40,000 & 30 & 0.15 & \\
\hline$>$ Ksh. 40,000 & 22 & 0.11 & \\
\hline \multicolumn{4}{|l|}{ Childs age (Months) } \\
\hline$<12$ months & 23 & 0.12 & \multirow{3}{*}{$\mathrm{p}=0.046$} \\
\hline $12-<36$ months & 30 & 0.15 & \\
\hline $36-<60$ months & 21 & 0.11 & \\
\hline
\end{tabular}

This research sought to determine whether social demographic factors influenced childhood diarrhea in the study area. Results showed that level of education, marital status and household net monthly income did not have significant association with childhood diarrhea in Kasarani study area $p>0.05$. However age of the child influenced childhood diarrhea $\mathrm{p}=0.046$.

\subsection{Childhood Diarrhea Risk Factors Associated with WASH Conditions}

Table 9. Relationship between diarrhea and WASH conditions.

\begin{tabular}{|c|c|c|c|}
\hline Indicator variable & Number of children & Diarrhea prevalence & Significance \\
\hline \multicolumn{4}{|c|}{ Household daily water consumption rate (litres/day } \\
\hline$<40$ & 23 & 0.12 & \multirow{3}{*}{$\mathrm{p}=0.001$} \\
\hline $41-<70$ & 40 & 0.21 & \\
\hline$>71$ & 30 & 0.15 & \\
\hline \multicolumn{4}{|l|}{ Method of water treatment } \\
\hline Boiling & 34 & 0.17 & \multirow{2}{*}{$\mathrm{p}=0.002$} \\
\hline Use of chemicals & 23 & 0.12 & \\
\hline Frequencies of water shortages & & & $\mathrm{p}=0.001$ \\
\hline Once daily & 26 & 0.13 & \\
\hline$>$ One day $<$ one week & 20 & 0.10 & \\
\hline$>$ one week & 24 & 0.12 & \\
\hline \multicolumn{4}{|l|}{ Type of the toilet } \\
\hline Pit latrine & 33 & 0.17 & \multirow{3}{*}{$\mathrm{p}=0.001$} \\
\hline Flush toilet & 21 & 0.11 & \\
\hline Others & 36 & 0.18 & \\
\hline Ground & 22 & 0.11 & \multirow{3}{*}{$\mathrm{p}=0.001$} \\
\hline Covered bin & 23 & 0.12 & \\
\hline Polythene bag & 30 & 0.15 & \\
\hline
\end{tabular}

One of the objectives of this study was to determine whether there was an association between Water, Sanitation, and Hygiene and childhood diarrhea. The findings were that (WASH) factors were found to be significantly associated with the childhood diarrhea. These factors were: Household daily water consumption rate (litres/day), Child's age, Method of water treatment, Frequencies of water shortages, type of the toilet and method of Storage of solid waste. The study observed that the higher the amount of safe water a household consumed per/day, the lower the risk of contracting diarrhea. Older Children were at a higher risk of contracting diarrhea compared to younger ones. Frequencies of water shortage were a risk factor for childhood diarrhea with frequencies of less than three days posing more risk for childhood diarrhea.

\section{Discussion}

\subsection{WASH Risk Factors Related to Childhood Diarrhea in the Study Environs}

All the households used piped water from Nairobi Water 
and Sewerage Company but there were significant differences with regard to water usage, shortage, frequency of supply and treatment. It was not clear why there was this difference given that one service provider was responsible but could be explained by infrastructural development, tariffs, and rations. It is worth noting that water supply to informal settlement of Kasarani occurred through public water taps and not household water taps. Commercial supply of water affect tariff. During field observations, most public water taps were under lock and key. These findings agree with a study [7], that observed that urban poor are normally disproportionately underserved with water services. With regard to access to Sanitation and Hygiene services, the study established a significant difference between access to Sanitation and Hygiene services and respective study environs, with majority from ISLI sharing the Sanitation facilities. This was even more important considering that the urban poor live in crowded slums and informal settlement where sanitation and hygiene services are particularly important for children's health. These findings supported both [15], on childhood diarrhea and [7], on Water, Sanitation hygiene which observed that without adequate quantities of Water and proper Sanitation and hygiene, infections such as diarrhea spread easily.

On diarrhea occurrence, the results show that most cases of childhood diarrhea were experienced in ISLI and HDLI compared with LDHI and MDMI respectively. Notably, these were the same areas where water availability was stressed besides other vulnerable environmental characteristics. This is a very important factor in transmission of waterborne and water-related diseases. These findings support several other studies that suggest that quality of water and the general level of household hygiene affect exposure to diarrhea pathogens [24]. These results showed that the age of a child presented a risk for childhood diarrhea. Children between the ages of 29 to 36 months were more likely to contract diarrhea. This could be attributed to the stage when the child is interacting with his environment hence vulnerability to contamination indicating poor and unhygienic environment. These findings confirm earlier studies [23], which found an association between the age of the child and diarrhea incidences suggesting that the ability of the child to interact with the environment may increase the probability of contamination.

Water treatment practices and methods were also observed to present a risk for childhood diarrhea with households using water settling method presenting the highest risk for childhood diarrhea. This can be explained that settling as a method of treating water does not eliminate all the possible water pathogens hence causing risk in the water uses. Quantities and frequencies of water supply also presented a risk for childhood diarrhea. Households consuming less than 60.75 litres of water per day presented a higher risk for childhood diarrhea. This was also the case with those experiencing water shortages for less than three days. This implied that less water implicated proper sanitation and household hygiene. Other factors that presented a risk for childhood diarrhea were the methods households stored their solid wastes which could have promoted insect vectors compromising Sanitation and hygiene practices. These results agreed [21], that observed that 23.3 million Kenyans lack access to safe drinking water and proper Sanitation resulting to several deaths (mostly children).

\subsection{Household Water Contamination Level in the Study Environs}

These results indicated that water sampled from LDHI was not contaminated. For the water sampled from the rest of the residential environs, both $\mathrm{E}$. coli and $\mathrm{T}$. coli bacteria were detected. Further, it was determined that contamination of water was more in the public tap water than from the household water container. It is therefore likely that due to seepage in the broken pipes, contamination was more likely to occur. These findings were inconsistent with the study [22], which suggested that risk of water contamination is higher in water containers than in water taps due to poor water storage and mishandling.

\section{Conclusion}

This study concluded that there was a relationship between the observed childhood diarrhea, water, sanitation and hygiene conditions prevailing in Kasarani, Nairobi County. The findings established that NWSCO was the main source of water supply for all the study environs. Regular water shortages were found to be more frequent in ISLI and HDLI study environs than LDHI and MDMI. Water treatment practices and methods across thy four residential environs presented a risk for childhood diarrhea. Age of a child presented a risk for childhood diarrhea with children between the ages of 29-36 months likely to contract diarrhea. Meanwhile, high rate of diarrhea occurrence in ISLI was attributed to inadequate quantities and qualities of water besides the other environmental factors. Meanwhile the microbial result in the study area was suspected to be a function of contamination in the distribution network or household and personal hygiene practices among the residents.

\section{Recommendations}

1. The study recommended for further study to determine to what extent income levels in the different residential environs in the study area affects childhood diarrhea,

2. There is need to establish the extent to which storage of solid waste within households in Kasarani affects childhood diarrhea,

3. There is need to determine to what extent the disparity and interruption of water supply by NWSCO to different residential environs in Kasarani impact on diarrhea among the under five

4. There is need to establish to what extent the type and adequacy of toilet facilities affect childhood diarrhea in Kasarani. 


\section{Acknowledgements}

Our appreciation goes to Mr Mical Kituva for his role in the collection of the study data.

\section{References}

[1] WHO (2009). The treatment of Childhood diarrhea. A manual for Physicians and other senior Health Workers. GENEVA: WHO.

[2] UNICEF/WHO (2008). Water, Sanitation and Hygiene, New York: UNICEF/WHO.

[3] WHO/UNICEF, (2005). Water, Sanitation and Hygiene. Children and Water global statistics, Switzerland: WHO.

[4] UNICEF/WHO (2009). Diarrhoea disease. USA; UNICEF/WHO.

[5] Black, R. E (20000. Diarrhoea disease. Infectious disease epidemiology, theory and practice. London: Aspect publishers.

[6] Hunter (1997). Waterborne disease, epidemiology and ecology, john willey and sons, USA.

[7] World Bank (2005). World Bank development indicators. Washington DC; WB.

[8] Curtis, V.\& Cairneross, S. (2003). Effects of washing hands with soap on diarrhea risk in the community: A systematic review, lancet infectious diseases. London: pubmed.

[9] Ingrid, I. (2008). Diarrhoea diseases. An overview of causes, systems and treatment. New York: Oxford University.

[10] AMREF. (2011). Integrated School Health. Kenya: AMREF.

[11] WHO/UNICEF (2006). Water, Sanitation and Hygiene: Children and water-global statistics (2009). WHO.
[12] WHO. (2005). Diarrhoea diseases. Geneva: WHO.

[13] WaterAid, (2008). Water and Sanitation Sep 2009. UK: WaterAid.

[14] Nyagetiria, A. D. (2009). Estimating burden of diarrhea associated with water, sanitation and hygiene among the under fives in residential environs of Nairobi. Nairobi: Kenyatta University.

[15] UNICEF. (2008). Water, Sanitation and Hygiene. Children and water global statistics, Switzerland: UNICEF.

[16] JICA, (2010). Integrated Solid Waste management of the City of Nairobi. JICA Project. Kenya: Nairobi.

[17] Kosek (2003). Division of geographic and international medicine. USA: University of Virginia.

[18] Mulligan, (2005). Water quality interventions to prevent diarrhea cost cost-effectiveness. Geneva, WHO.

[19] Pruss, (2006). Safewater, better health. Costs and benefits and sustainability of intervention to protect and promote health (1246-1255). Geneva: WHO.

[20] HMIS, (2010). Health Management Information Systems. Epidemiology and disease control. Nairobi: PhD.

[21] Gwako. (2010). Grand water abstractions in Kenya 2010. Kenya: Nairobi.

[22] Feachem RG. (1987). Diarrhoea Morbidity patterns in Central region of Ghana. NCBI, Ghana.

[23] Tagoe (1995). Risk factors associated with under five in rural Zimbabwe. Harare, Zimbabwe.

[24] Diame (1990). Risk factors associated with under five diarrhea in Kenya. UON, Kenya. 